\title{
A State-Of-The-Art Review on Retrofitting Beam-Column Joint Using GFRP with NSM Technique under Seismic Loading
}

\author{
Asma Nabila binti Abd Kader, S. A. Osman, and M. Y. M. Yatim
}

\begin{abstract}
Recent development of seismic action has highlighted the consequences of poor performance of beam-column joints, which has been identified as the main principle cause of failure when the frame is subjected to earthquake loading. This paper summarized numerous past studies according to the type of beam-column joint, retrofitting techniques and fiber reinforced polymer (FRP). For this purposes, 100 research works from previous researchers were collected. The structural behavior of beam-column joint has been extensively studied in the past decades. Experimental and analytical solutions have been conducted and proposed by many researchers to understand the behavior of the beam-column joint. However, Near Surface Mounted (NSM) technique using Glass Fiber Reinforced Polymer (GFRP) in retrofitting beam-column joint has yet to be investigated. Therefore, this study is proposed for future research. In-depth investigations must be carried out as to gain more thorough understanding on the behavior of retrofitted beam-column joint using GFRP with NSM technique.
\end{abstract}

Index Terms-Exterior beam-column joint, glass fiber reinforced polymer (GFRP), near surface mounted (NSM), seismic loading.

\section{INTRODUCTION}

The beam-column joint becomes an important part of the structure as the connection must be able to resist and sustain any loads transmitted from the beams and columns. Therefore, design of the beam-column joint is a crucial part for earthquake resistance of modern structures such as reinforced concrete, steel and precast concrete building. The severe damage exhibited by reinforced concrete (RC) framed buildings under earthquakes has frequently proven the high vulnerability of existing structures toward seismic actions, mainly due to an unsatisfactory behavior of beam-column joints. The condition is mostly found in the case of corner joints or those belonging to façade frames, only partially confined for the absence of beams on the four joint faces [1].

\section{A. Earthquake in Malaysia}

Generally, Malaysia is known as one of the lucky country in the world due to its location outside the Pacific Ring of Fire, but it is not a guarantee that the country is safe from

Manuscript received March 8, 2018; revised May 12, 2018. This work was supported in part by the Ministry of Science, Technology \& Innovation Malaysia (MOSTI) under Grant 04-01-02-SF1298.

Asma Nabila binti Abd Kader, S. A. Osman, and M. Y. M. Yatim are with the Department of Civil \& Structural Engineering, Universiti Kebangsaan Malaysia, Malaysia (e-mail: asmanabila.kader@gmail.com, saminah@ukm.edu.my, mymy@ukm.edu.my).

earthquake. On 5th June 2015, the latest earthquake struck Ranau, Sabah, Malaysia with a magnitude of 6.0 has lasted for 30 seconds. The earthquake was the strongest to affect Malaysia since 1976. Serious damage occurred to the hostels and rest house near the summit of Mount Kinabalu. Buildings were similarly affected by the earthquake in Kota Belud and Tuaran.

The current building code of Malaysia does not consider the earthquake in its code provisions. Resident's safety is an important indication in structural building design, therefore a detail analysis of building like hospital in earthquake situations need to be carried out. This is to ensure the important buildings are safe when earthquake suddenly occurred in Malaysia. Existing and future buildings in Malaysia need to have a structural performance that can be assessed for the building's ability to withstand the earthquake aftershock.

\section{BEAM-COLUMN JOINT}

\section{B. Type of Beam-column JOINT}

Beam-column joint is a very critical elements in a reinforced concrete structural frame where the structures intersect in three directions. In a moment resisting frame, three types of connections can be classified as interior joint, exterior joint and corner joint as shown in Fig. 1 [2].

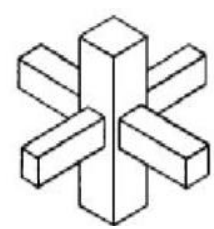

Interior

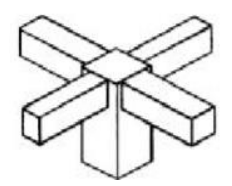

d) "Roof'-interior e) 'Ro

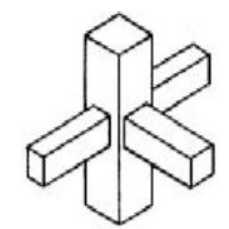

c) Corner

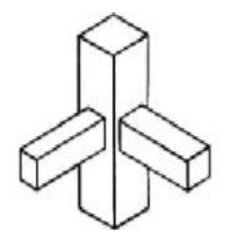

b) Exterior

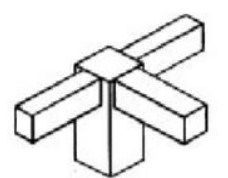

f) "Roof"-corner

Fig. 1. Types of joints in a frame [2].

\section{Forces of Beam-column Joint}

The forces acting on a beam-column joint depends on the type of the connection and the type of loading acting on it. The forces on an interior joint subjected to gravity loading can be depicted as shown in Fig. 2(a). The tension and compression forces from the beam ends and axial loading from the columns can be transmitted directly through the joint. 
In the case of lateral (or seismic) loading, the equilibrating forces from beams and columns, as shown in Fig. 2(b) develop diagonal tensile and compressive stresses within the joint.

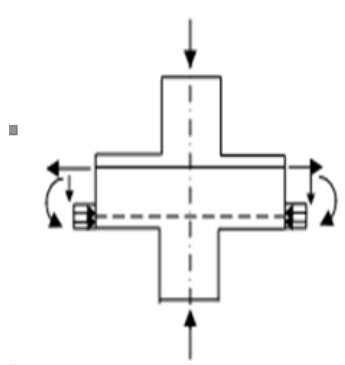

Gravity loading

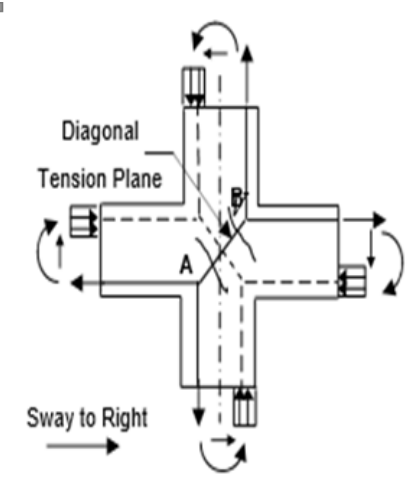

b) Seismic loading
Fig. 2. Forces in interior beam-column joint [3]

The forces acting on an exterior joint can be described as shown in Fig. 3(a). The shear force in exterior joint gives rise to diagonal cracks thus requiring reinforcement of the joint. The detailing patterns of longitudinal reinforcements significantly affect the efficiency of the joint. Some of the detailing patterns for exterior joint are shown in Fig. 3(b) and Fig. 3(c).

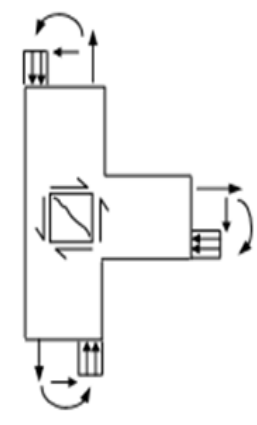

a) Forces
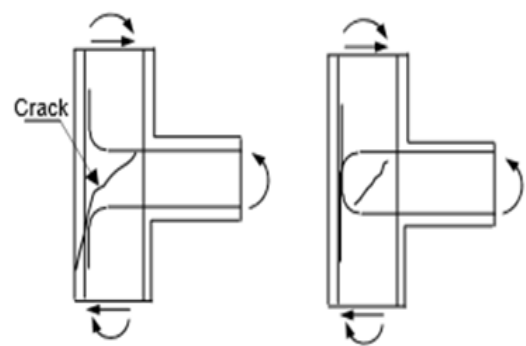

b) Poor detail
Fig. 3. Exterior beam-column connections [3].

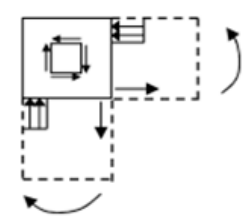

(a) Opening Joint (Top View)

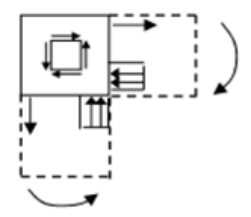

(c) Closing Joint (Top View)

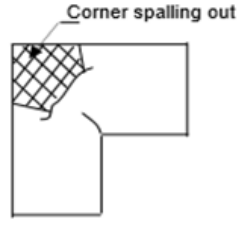

(b) Cracks in an Opening Joint

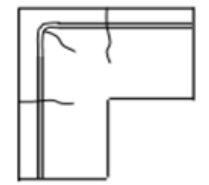

(d) Cracks in a Closing Joint
Fig. 4. Corner beam-column joint [3].

The forces in a corner joint with a continuous column above the joint can be understood in the same way as that in an exterior joint with respect to the considered direction of loading. In considering joints at the intersection of a beam and column at a corner of a rigid frame, it is necessary to distinguish between joints that tend to be opened by the applied moments and those tend to be closed by the applied moments. Opening joints occur at the corners of frames and in L-shaped retaining walls. The elastic stresses in a closing corner joint are exactly opposite to those in an opening corner joint [3]. The stresses and cracks developed in such a joints are shown in Fig. 4.

\section{RETROFITTING TECHNIQUES UNDER SEISMIC LOADING}

\section{A. Jacketing}

Jacketing technique is the most popular method for strengthening of building columns. There are three types of jacketing namely steel jacketing, concrete jacketing and FRP jacketing. The purpose for jacketing is to increase concrete confinement, shear strength and also flexural strength.

Fig. 5 shows an example of a classic repair of the columns by jacketing (additional vertical bars and stirrups and applying an additional concrete layer).
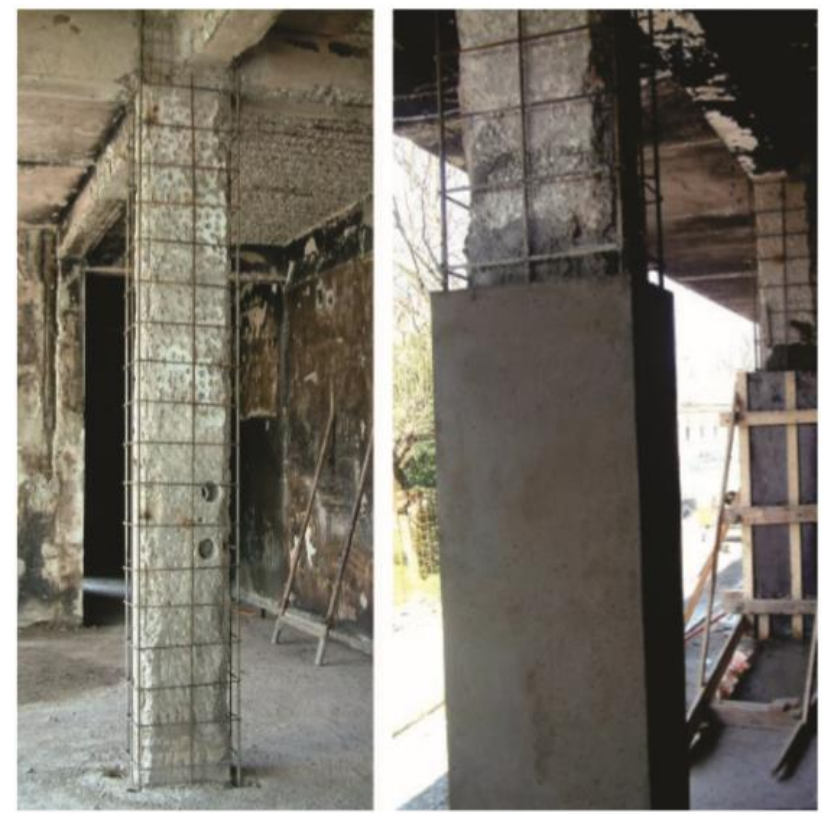

Fig. 5. Classic way of repairing columns by jacketing [4].

\section{B. Wrapping}

FRP wrapping offer an attractive cost-effective alternative as they can be rapidly fabricated, speedily applied and result in minimal traffic disruption. Fig. 6 shows the application method of wrapping FRP for damaged specimen on site [5].

Application of FRPs started with rounding the section corners to prevent the tearing of FRP sheets due to sharp corners of the RC sections. Then, a thin layer of undercoat was applied on the corresponding $\mathrm{RC}$ component to be repaired. After that, epoxy based repair and anchorage mortar was applied to obtain smooth surface. Finally, FRP sheets were saturated with epoxy and applied to the corresponding member surface. In order to get a good bonding between FRP sheets and surfaces, a hand roller was used to remove air and stick them properly. 

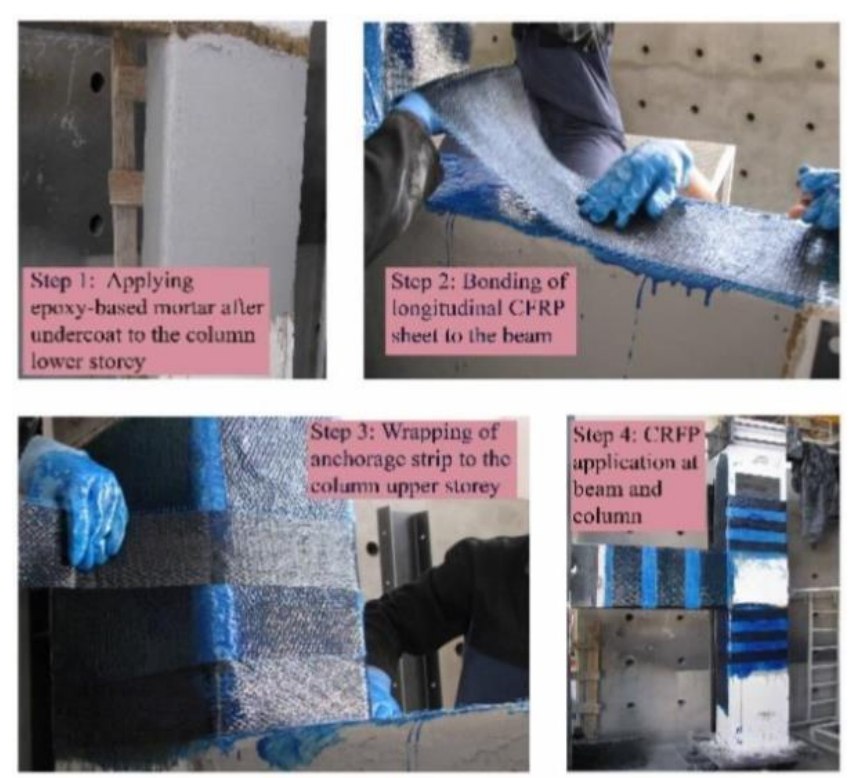

Fig. 6. Application method of FRP wrapping [5].

\section{Web-Bonded}

Web-bonded FRP is one of the few possible strengthening methods that can be used when an inadequately detailed joint is damaged causing severe degradation of the joint's structural strength. P.J. Lim et.al [6] carried out investigation experimentally on beam-column joints which the column is wider than the beam hence hindering the proper bonding of the FRP sheet(s) to the concrete at the location of the abrupt change in width. Fig. 7 shows beam-column joints were built with this change in width, patched with grout transition slopes and retrofitted with web-bonded Carbon FRP (CFRP). Testing shows that the CFRP sheets were still prone to delamination.

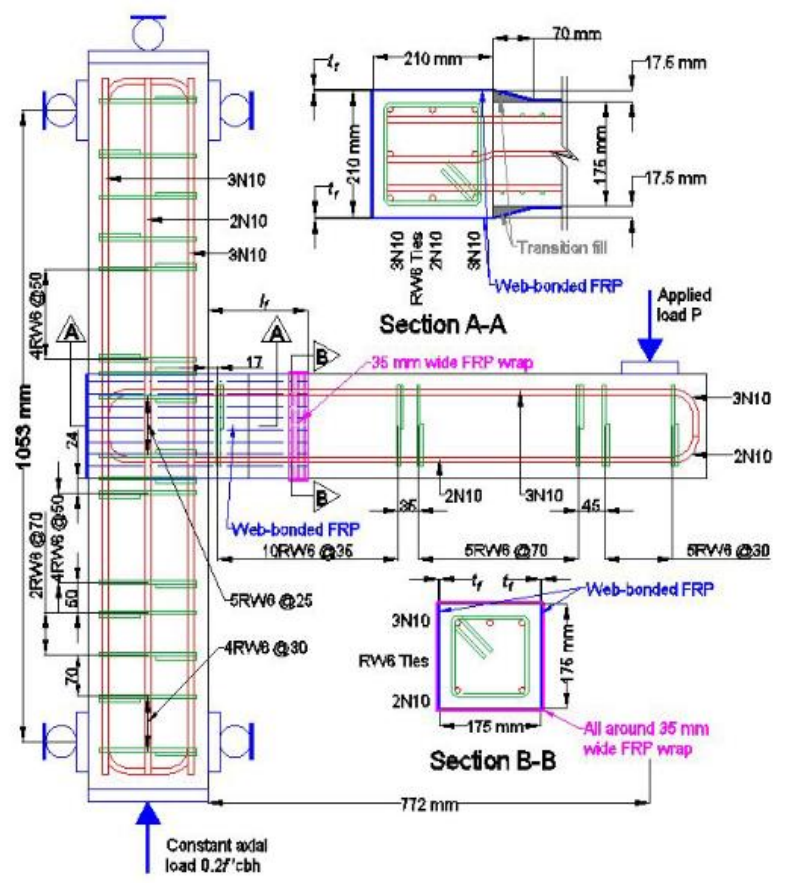

Fig. 7. Details of specimen patched with grout fill and retrofitted with 3 layers of web-bonded CFRP [6].

\section{Flange-Bonded}

S. Zarandi and Maheri [7] carried out numerical studies to investigate the effect of flange-bonded scheme on reinforced concrete joints in relocation the plastic hinge into the beam. FRP laminates are placed on the top and bottom flanges of the beams ends joining the joint and are extended so that they cover parts of the adjoining column faces. The end of the FRP overlay is anchored to the column using FRP strips wrapped around the column as seen in Fig. 8. Their results showed that the flange bonded scheme is outperform the web-bonded technique regarding capacity, ductility and the performance level, as well as cost.

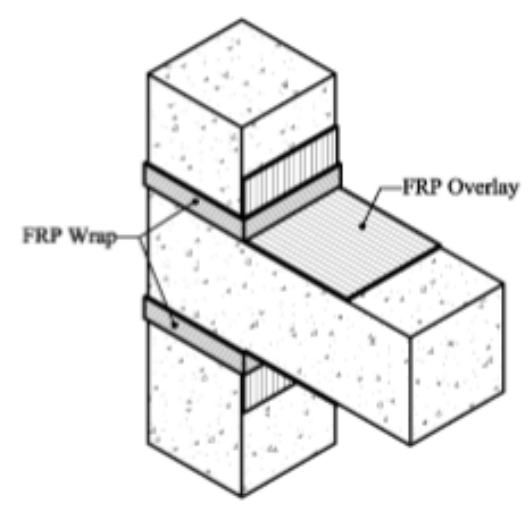

Fig. 8. Flange-bonded scheme [7].

\section{E. Externally-Bonded}

Externally bonded FRP are widely used for strengthening concrete structures. The materials may be formed into composite plates or shells, which are then bonded to the concrete surface. Alternatively, the composite may be formed in situ, with the fibers in the form of fabrics impregnated with resin and applied to the concrete surface.

Fig. 9a and $9 \mathrm{~b}$ shows damaged specimens in experimental work by Flora Faleschini et.al [8] that were tested under quasi static cyclic lateral loading. Fig. 9c and 9d shows the joint that were repaired with externally bonded carbon-FRP composite $[8]$.

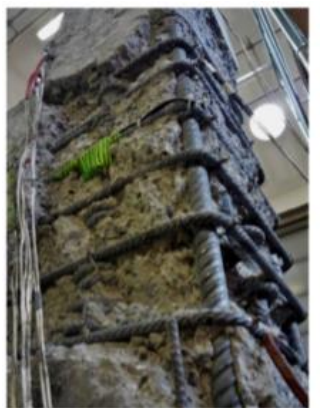

a)

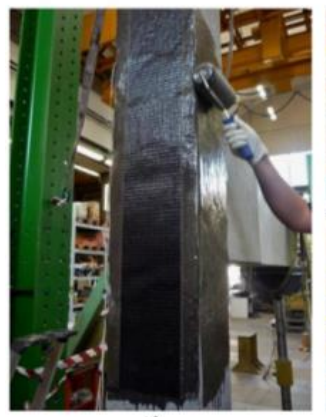

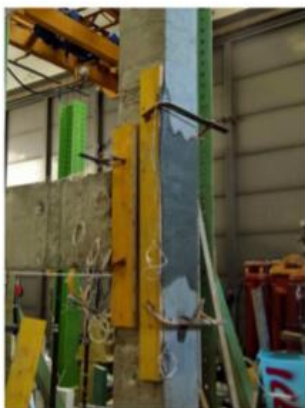

b)

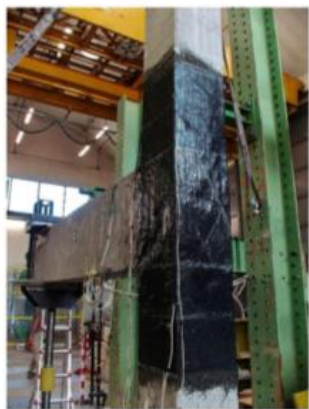

Fig. 9. Specimens repaired with externally bonded [8] 


\section{F. Near Surface Mounted (NSM)}

This method is often able to utilize a greater proportion of the full strength of the bonded FRP because of superior bond characteristics, which help to prevent premature de-bonding failures. NSM techniques have become popular due to its specific bond characteristics which can enable more use of FRP. NSM FRP technique does not require extensive surface preparation work and, after groove cutting, requires minimal installation time compared to externally bonded FRP laminates because the use of primer and putty is normally not necessary. Fig. 10 and 11 shows rehabilitation of RC deep beams for shear after pre-crack using NSM by Anis and Thaer [9].

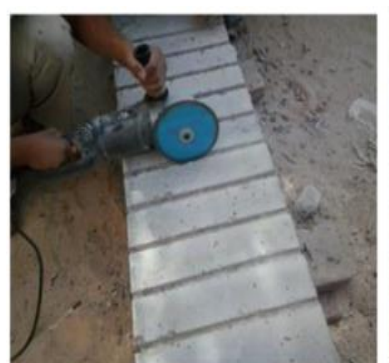

(a)

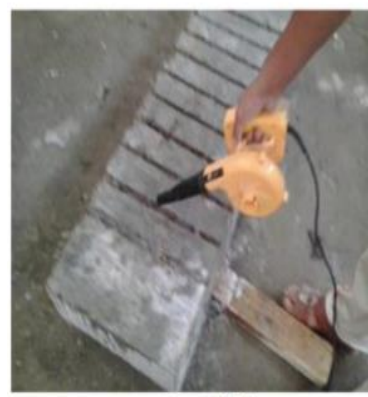

(c)

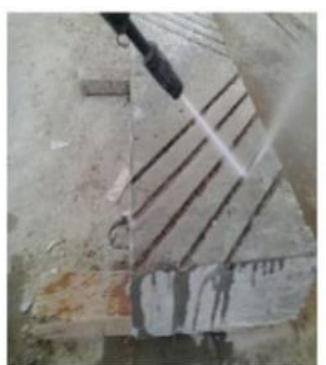

(b)

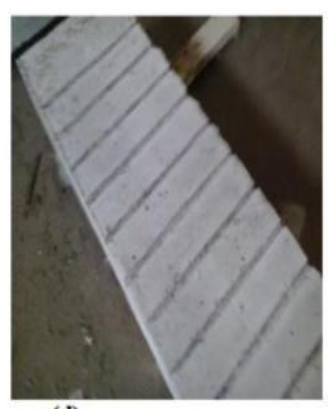

(d)

Fig. 10. Grooves preparation on beam side face [9].

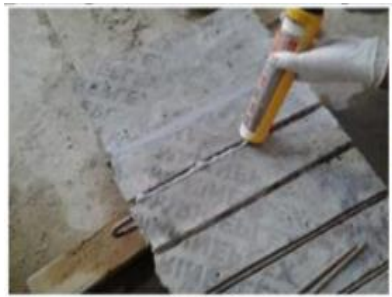

(a)

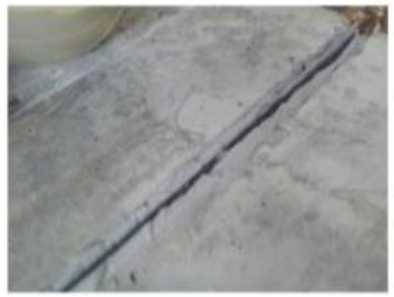

(c)

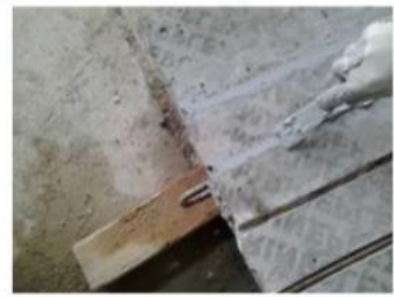

(e)

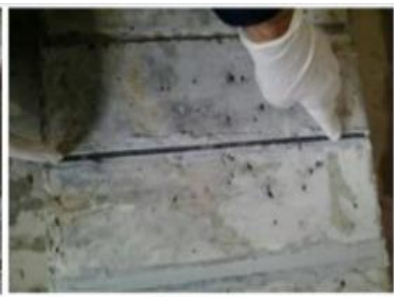

(b)

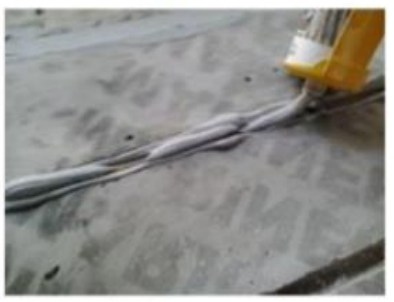

(d)

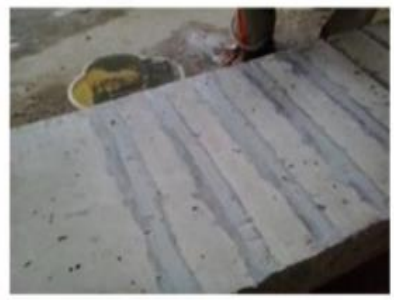

(f)
Fig. 11. Application of Near Surface Mounted technique [9].

\section{FIBER REINFORCED POLYMER USED TO RETROFIT BEAM-COLUMN CONNECTION}

In recent years, utilization of FRP sheets has become one of the commonly preferred seismic retrofit approaches for reinforced concrete columns and beams, particularly for enhancing ductility and shear strength. A new technique has emerged recently which uses FRP sheets to strengthen the beam-column joints which have a number of favorable characteristics such as ease to install, immunity to corrosion and high strength.

Comparing with traditional rehabilitation techniques, the FRP composites have high specific strength/stiffness, flexibility in design and replacement as well as robustness in unfriendly environments. There are few examples of FRP used in retrofitting beam-column joints:

\section{A. Carbon Fiber Reinforced Polymer (CFRP)}

In recent decades, there has been an increasing interest in the use of CFRP, in the aerospace, renewable energy and other industries, due to low weight and relatively good mechanical properties compared to traditional metals.

Ebrahim and Hashim [10] used CFRP sheets to wrap the critical regions of the beam, column and the joint zone of the examined sub-assemblages for confining these regions. The results showed that the method is effective and capable of restoring or even upgrading load-carrying capacity and initial stiffness of damaged joints.

\section{B. Glass Fiber Reinforced Polymer (GFRP)}

Applications of GFRP elements have grown steadily during the last years, as they became extremely popular in different areas of the aerospace, automotive, marine, oil and gas and civil construction industries. An experimental and analytical program carried out by Omar A.M Elnawawy et.al [11] focused on upgrading an ordinary exterior beam-column joint to withstand the lateral load expected in moderate earthquake zones using CFRP and GFRP wraps. The use of CFRP wrap resulted in a higher increase in the strength, while the GFRP wrap can result in an appreciable increase in strength with the advantages of lower cost and higher chemical resistance. More than one layer of GFRP can be used to achieve high increase in the strength with lower cost compared to using CFRP.

\section{Aramid Fiber Reinforced Polymer (AFRP)}

Aramid fiber has high strength, high elastic modulus, and high abrasion resistance which make these fibers well suited for FRP reinforcement and strengthening applications. The key property of aramid fiber reinforced composites in comparison with other fiber containing polymers is the cost-effective performance at reduced weight. Aramid fibers possess a unique combination of high strength and modulus with low density and high elongation that results in improved impact resistance of the respective composites. Aramids high tensile strength lends itself well to the manufacture of sporting goods where weight can be reduced significantly while providing greater tear strength and puncture resistance than fiberglass composites [12].

\section{Basalt Fiber Reinforced Polymer (BFRP)}

BFRP is a relative newcomer to FRP and structural 
composites. According to Kunal Singha [13], basalt fiber is capable to withstand very high temperature and can act as fire blocking element. It has a similar chemical composition as glass fiber but has better strength characteristics, and unlike most glass fibers is highly resistant to alkaline, acidic and salt attack making it a good candidate for concrete, bridge and shoreline structures. Basalt as a fiber used in FRPs and structural composites has high potential and is getting a lot of attention due to its high temperature and abrasion resistance.

\section{E. Hybrid Fiber Reinforced Polymer}

The hybrid fiber reinforced polymers have been prepared to enhance the mechanical, thermal, damping properties compared to single-fiber reinforced composites. The fiber reinforced hybrid composites consist of two or more fiber in a matrix system. The different fibers were reinforced with suitable matrix for preparing the hybrid composites using various manufacturing methodology. The hybrid composites are used for many application and replacing wood, wood fiber composites and conventional materials [14].

\section{DISCUSSIONS}

Having discussed the effect of forces for beam-column joint and various retrofitting techniques of FRP under seismic loading, 100 research papers from previous studies related to that aspects were collected. The studies were then summarized according to the type of beam-column joint, retrofitting techniques and FRP used in their work.

\section{A. Beam-Column Joint}

During an earthquake, reinforced concrete (RC) buildings are subjected to lateral loads that can cause considerable damage and lead to the partial or total collapse of the structure. Among the elements of the building, beam-column joints are found to be one of the most critical structural components [15].

Out of all past studies, 63 studies investigated on repairing exterior beam-column joints, 20 research works on retrofitting interior joints, 11 studies on rehabilitating corner joints and 6 research works carried out on repairing $\mathrm{RC}$ frame which consist both interior and exterior beam-column joints as shown in Chart 1.

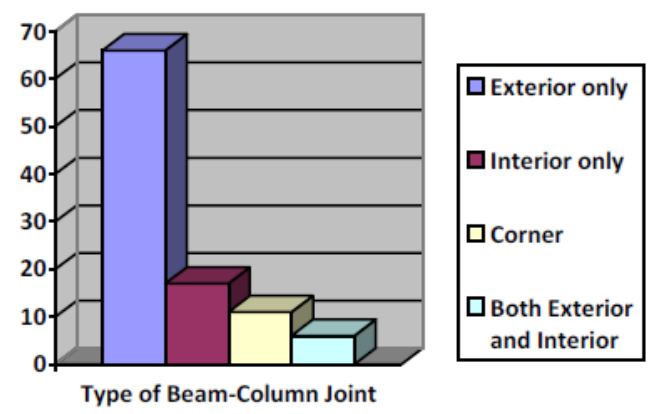

Chart 1. Type of beam-Column joint.

From Chart 1, it shows that most of researchers carried out investigation in retrofitting the exterior beam-column joint. This type of joint is highlighted due to its vulnerability under seismic loading. This may be attributed to insufficient strength to withstand the lateral loads by the connection due to the reason of being poor detailing without consideration to seismic provisions. This problem leads to decrease in ductility with diagonal shear developed in the connection leading to catastrophic failures [16]. Accordingly, when large lateral forces are applied during earthquakes, such joints may severely get damaged. Moreover, repairing damaged joints is difficult, and thus damage must be avoided by sufficient design and detailing in advance.

\section{B. Retrofitting Techniques}

Depending on the level of affectation of the structure, demolition and replacement of the building might be required. However, this solution is expensive and less time efficient and should be used only when the repair of the structure is not possible. Otherwise, the repair of the damaged structure provides more time or cost efficient option. There are many techniques which can be employed to rehabilitate weak beam-column joints. Several strengthening techniques have been investigated in which 55 of studies carried out on wrapping techniques, 30 research works on externally-bonded technique, 20 studies on jacketing technique, 8 studies on web-bonded technique, 4 studies on flange-bonded technique and 6 investigated on NSM technique as shown in Chart 2.

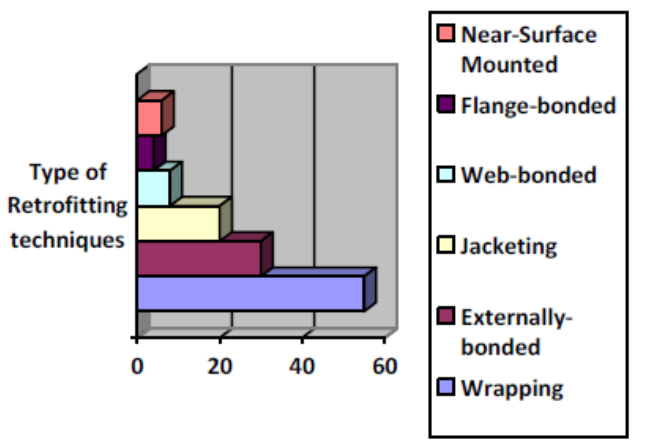

Chart 2. Type of retrofitting techniques.

From Chart 2, wrapping technique is seen to be the most used technique by researchers followed by externally-bonded and jacketing techniques. Extensive experimental studies have shown that these techniques can significantly increase the stiffness and load carrying capacity of the retrofitted structures. However, there have been reports of reduction in ductility associated with brittle behavior due to bond failure and FRP rupture [17].

In order to overcome these drawbacks, to improve utilization of the FRP materials, and to ensure higher durability, NSM technique is seen as the least and newest alternative technique for retrofitting the exterior beam-column joints. The NSM technique consists of inserting FRP strips into pre-cut grooves through the concrete cover at the tension side of the members to be strengthened. A high-strength epoxy adhesive is used to bond the FRP strips to the concrete. This method is simple and considerably enhances the bond of the FRP reinforcements since both faces of the strips are bonded to the concrete [18].

However, there is limited experimental work investigating the behavior of reinforced concrete beam column connection 
strengthened using NSM technique. Typically, NSM technique is carried out only in beams or slabs. An experimental investigation by A.A Khalil et.al [19] is carried out on the behavior of reinforced concrete continuous beams strengthened with NSM technique revealed that increase of hogging NSM-CFRP strip bonded length increased the failure load, decreased the crack width and delayed the slippage ignition. A more thorough research is needed to have a better analysis and finding in retrofitting beam column connection using NSM technique.

\section{Fiber Reinforced Polymer (FRP)}

A new technique of using fiber reinforced polymer (FRP) has emerged recently to strengthen the beam-column joints which have a number of favorable characteristics such as ease to install, immunity to corrosion and high strength. With FRP composites it is possible and also necessary to achieve the best strengthening results by optimizing the constitute materials and architecture. Various past studies on the use of FRP to retrofit beam-column joints have been gathered in which 84 studies used Carbon FRP, 29 works on Glass FRP, 4 studies used hybrid FRP, and only 1 study on each for Basalt FRP and Aramid FRP as shown in Chart 3.
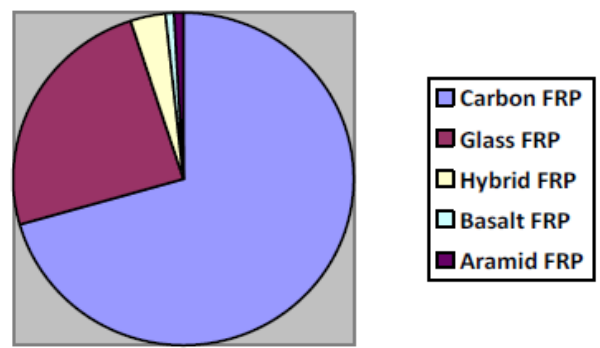

Chart 3. Type of FRP used to retrofit beam-column joint.

Carbon FRP seen to be the most and likely used by researchers due to low weight and relatively good mechanical properties compared with traditional metals. However, it is very expensive but commonly used wherever high strength and rigidity is required. In case of pre-stressing construction it cannot be used due to difficulties in anchorage of strands. Besides, it also has no endurance limit when exposed to cyclic loading.

This is proven according to experimental work by Ebrahim and Hashem [20], which they studied the usage of CFRP on shear deficient exterior beam-column joints. Their study shown that repairing the joints using CFRP laminates is not applicable in damage levels higher than the repair-ability performance level.

The use of GFRP fabric was primarily attempted as the strengthening materials due to its properties which are lightweight, extremely strong, and robust materials. In addition, due to their non-corrossive nature, they are particularly suited for harsh environments where steel reinforcement is prone to corrosion. Besides, GFRP use as structural reinforcement may offer life-cycle cost benefits for certain structures as maintenance to repair corroded reinforcement is not necessary [21].

An attempt has been made to carry out an investigation on beam column joint specimens wrapped with GFRP by $\mathrm{T}$.
Mariselvam and N.Sakthieswaran [22]. The experimental results clearly demonstrate that GFRP wrapping can enhance the structural performance of RC beam-column joint under static loading and increasing the number of GFRP layers increase the axial compressive strengths of the beam column joint.

\section{CONCLUSION}

The structural behavior of beam-column joint has been extensively studied in the past decades. Experimental and analytical solutions have been conducted and proposed by many other researchers to understand the behavior of the beam-column joint. However, NSM technique using GFRP in retrofitting beam-column joint has yet to be investigated. This study was pointed out for future research due to limited number and gaps found. In-depth investigations must be undertaken to gain a more thorough understanding of the results on behavior of retrofitted beam-column joint using GFRP with NSM technique.

\section{ACKNOWLEDGMENT}

The authors would like to thankfully acknowledge the financial support ScienceFund grant (04-01-02-SF1298) received from the Ministry of Science, Technology \& Innovation Malaysia (MOSTI).

\section{REFERENCES}

[1] A. D. Vita, A. Napoli, and R. Realfonzo, "Full scale reinforced concrete beam-column joints strengthened with steel reinforced polymer systems," Journal Frontiers in Materials, vol. 4, 2017.

[2] A. K. Tiwary, A. K. Tiwary, and M. Mohan, "A review paper on strengthening of beam column joint upgraded with CFRP sheets," IOSR Journal of Mechanical and Civil Engineering, National Conference on Advances in Engineering, Technology \& Management (AETM'15), civil group, volume 2, pp. 20-26, 2015.

[3] J. G. Macgregor and J. K. Wight, Reinforced Concrete Mechanics and Design, Prentice Hall Inc, 6th edition, 2012, ch 17, pp.953-966.

[4] V. Radonjanin, M. Malešev, R. Folić, and I. Lukić, "Assessment and repair of the bearing structure of the Gradiska cultural centre after fire," Tehnički vjesnik, vol 21, 2014.

[5] O. Yurdakul and O. Aysar, "Structural repairing of damaged reinforced concrete beam column assemblies with CFRPs," Structural Engineering and Mechanics, vol. 54, pp. 521-543, February 2015.

[6] P. J. Lim, S. S. Mahini, and H. R. Ronagh, "Anchorage of web-bonded CFRP retrofitting on $\mathrm{RC}$ joints with variable column \& beam widths and with cross-beams present," presented at the Fourth Asia-Pacific Conference on FRP in Structures (APFIS 2013), Melbourne, Australia, 11-13 December 2013

[7] S. Zarandi and M. R. Maheri, "Seismic performance of RC frames retrofitted by FRP at joints using a flange-bonded scheme," IJST, Transactions of Civil Engineering. vol. 39, no. C1, pp. 103-123, September 2014

[8] F. Faleschinia, J. Gonzalez-Librerosa, M. A. Zaninia, P. Zampieria, and C. Pellegrinoa, "Experimental behavior of damaged RC beam-column joints repaired with FRP composites," presented on conference XVII Convegno ANIDIS - L'Ingegneria Sismica in Italia, At Pistoia, 17 - 21 September 2017.

[9] A. A. M. Ali and T. M. Mezher, "Rehabilitation of RC deep beams for shear after per-crack by near surface mounted CFRP rods," International Journal of Engineering Research and Technology, vol.4, pp. 350-353, September 2015.

[10] E. Z. Beydokhty and H. Shariatmadar, "Behavior of damaged exterior RC beam-column joints strengthened by CFRP composites," Latin American Journal of Solids and Structures, vol. 13, 2016.

[11] O. A. M. Elnawawy, A. H. A. A. Zaher, and E. H. M. Zahran, "Response of seismically detailed RC beam column joints strengthened with FRP," International Journal of Innovative Research 
in Science, Engineering and Technology, vol. 4, no. 9, pp. 8922-8933, September 2015

[12] Z. Z. Denchev and N. Dencheva, "Manufacturing and properties of aramid reinforced polymer composites," pp. 465-530.

[13] K. Singha, "A short review on basalt fiber," International Journal of Textile Science, vol. 1, no. 4, pp. 19-28, 2012.

[14] T. P. Sathishkumar, J. Naveen, and S. Satheeshkumar, "Hybrid fiber reinforced polymer composites - A review," Journal of Reinforced Plastics and Composites, vol. 33, no. 5, pp.454-471, January 2014.

[15] H. Sezen, "Repair and strengthening of reinforced concrete beam-column joints with fiber reinforced polymer composites,' Journal of Composites for Construction, vol.16, pp. 499-506, October 2012.

[16] M. N. S. Hadi and T. M. Tran, "Retrofitting non seismically detailed exterior beam-column joints using concrete covers together with CFRP jacket," Construction and Building Materials, vol. 63, pp. 161-173, April 2014.

[17] A. M. Morsy, K. M. Helm, N. H. El-Ashkar, and M. Nada, "Flexural strengthening for RC beams using CFRP sheets with differen bonding," presented at the International Conference on Advanced in Structural and Geotechnical Engineering (ICASGE'15), Hurghada, Egypt, April 2015.

[18] A. M. Khalifa, "Flexural performance of RC beams strengthened with near surface mounted CFRP strips," Alexandria Engineering Journal, vol. 55, pp. 1497-1505, February 2016.

[19] A. Hakim A. K. Khalil, E. E. Etman, and A. H. Elmasry, "Behavior of reinforced concrete continuous beams strenghened with near surface mounted reinforcement," presented at the International Conference on Advanced in Structural and Geotechnical Engineering (ICASGE'15), Hurghada, Egypt, April 2015.

[20] E. Z. Beydokhti and H. Shariatmadar, "Strengthening and rehabilitation of exterior RC beam-column joints using carbon-FRP jacketing," Materials and Structures, vol. 49, pp. 5067-5083. March 2016.

[21] V. J. Worner, "Use of glass fibre reinforced polymer (GFRP) reinforcing bars for concrete bridge decks," Master dissertation, Department of Civil and Natural Resources Engineering, University of Canterbury, New Zealand, 2015.
[22] T. Mariselvam and N. Sakthieswaran, "Experimental investigation on GFRP wrapped R.C beam column joint," International Journal of Engineering Research (IJOER), vol. 1, April 2015.

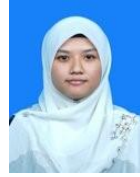

Asma Nabila binti Abd Kader is graduated from Universiti Kebangsaan Malaysia, Bandar Baru Bangi in Selangor, Malaysia in 2013 with BEng (Hons) in civil and structura engineering.

She has three years of experience working as site engineer for high-rise project and a member of Board of Engineers Malaysia (BEM). Currently, she further her studies in MSc in structural engineering in Universiti Kebangsaan Malaysia

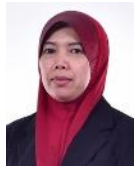

Siti Aminah Osman (S. A. Osman) is graduated from Universiti Teknologi Malaysia in 1992 with BEng (Hons) in civil engineering, MSc in structural engineering from Unversity of Bradford, UK (1995) and $\mathrm{PhD}$ in civil \& in 2006 . structural engineering from Universiti Kebangsaan Malaysia

She is now an associate professor in the Department of Civil and Structural Engineering, faculty of Engineering and Built Environment, Universiti Kebangsaan Malaysia (UKM) and a member of Board of Engineers Malaysia (BEM). Currently she is the head of Industry and Community Partnership of the faculty. Her interest is in structural engineering, earthquake and wind engineering, industrial building system (IBS) construction and engineering education.

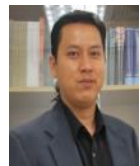

Mohd Yazmil Md Yatim is graduated from Universiti Kebangsaan Malaysia in 2006 with BEng (Hons) in civil and structural engineering, MSc in structural engineering from Universiti Teknologi Malaysia in 2009 and $\mathrm{PhD}$ in civil \& structural engineering from Universiti Kebangsaan Malaysia in 2014

He is now a senior lecturer at the Department of Civil and Structural, Faculty of Engineering and Built Environment, Universiti Kebangsaan Malaysia (UKM) and has taught a number of structural engineering courses at undergraduate and post-graduate levels. His research interests are in the areas of structural stability, steel plated structures, composite construction and computational analysis. 